\title{
Dementia in Down's syndrome: an MRI comparison with Alzheimer's disease in the general population
}

\author{
Diane Mullins ${ }^{1,2^{*}}$, Eileen Daly ${ }^{1}$, Andrew Simmons ${ }^{3,4}$, Felix Beacher ${ }^{1}$, Catherine ML Foy ${ }^{5}$, Simon Lovestone ${ }^{4,6}$, \\ Brian Hallahan ${ }^{7}$, Kieran C Murphy ${ }^{2}$ and Declan G Murphy ${ }^{1,4}$
}

\begin{abstract}
Background: Down's syndrome (DS) is the most common genetic cause of intellectual disability. People with DS are at an increased risk of Alzheimer's disease (AD) compared to the general population. Neuroimaging studies of $A D$ have focused on medial temporal structures; however, to our knowledge, no in vivo case-control study exists comparing the anatomy of dementia in DS to people with AD in the general population. We therefore compared the in vivo brain anatomy of people with DS and dementia (DS+) to those with AD in the general population.
\end{abstract}

Method: Using MRI in 192 adults, we compared the volume of whole brain matter, lateral ventricles, temporal lobes and hippocampus in DS subjects with and without dementia (DS+, DS-), to each other and to three non-DS groups. These included one group of individuals with AD and two groups of controls (each age-matched for their respective DS and general population AD cohorts).

Results: AD and DS+ subjects showed significant reductions in the volume of the whole brain, hippocampus and temporal lobes and a significant elevation in the volume of the lateral ventricle, compared to their non-demented counterparts. People with DS+ had a smaller reduction in temporal lobe volume compared to individuals with AD.

Conclusions: DS+ and AD subjects have a significant reduction in volume of the same brain regions. We found preliminary evidence that DS individuals may be more sensitive to tissue loss than others and have less 'cognitive reserve'.

Keywords: Dementia, Imaging, Intellectual disability

\section{Background}

Down's syndrome (DS) is associated with trisomy of chromosome 21 and occurs in approximately 1 per 1,000 live births. It is the most common genetic cause of intellectual disability. People with DS encounter an additional disease burden because they have a significantly increased risk for developing Alzheimer's disease (AD) in later life. In the general population, approximately $10 \%$ of 65 -yearolds and $40 \%$ of 80 -year-olds, develop symptoms of AD [1]. In contrast, the incidence of $\mathrm{AD}$ in people with $\mathrm{DS}$ is estimated to be three to five times higher. For example, at autopsy, the presence of Alzheimer-type neuritic plaques and neurofibrillary tangles have been reported in the brains of $7.5 \%$ of people with DS as early as the second

\footnotetext{
* Correspondence: dianetmullins@rcsi.ie

'Department of Forensic and Neurodevelopmental Sciences, Section of Brain Maturation, Institute of Psychiatry, De Crespigny Park, London, England, UK ${ }^{2}$ Department of Psychiatry, Royal College of Surgeons in Ireland, Education and Research Centre, Beaumont Hospital, Dublin 9, Ireland

Full list of author information is available at the end of the article
}

decade of life, with a rise in prevalence to $80 \%$ of cases by the fourth decade and to $100 \%$ in individuals over 60 years of age [2].

The markedly high frequency of $\mathrm{AD}$ neuropathology and early onset of dementia in DS is poorly understood. Likely explanations, however, include a genetically determined elevation in risk factors for $\mathrm{AD}$, and/or having less cognitive reserve due to a combination of these vulnerability factors and a pre-existing intellectual disability (mental retardation). For example, a significant proportion of the increased genetic risk for individuals with DS to develop dementia is probably explained by having trisomy of genes carried on chromosome 21 that are implicated in AD. Hence, it has been hypothesised that the presence of an extra copy of the amyloid precursor protein (APP) gene in individuals with DS leads to increased formation of amyloid plaques, neuronal death and clinical $\mathrm{AD}[3,4]$. Similarly, trisomy of the myo-inositol (mI) transporter protein [5] is associated with an increase in brain $\mathrm{mI}$, a 
compound that modulates neuronal development and survival, cellular osmolarity, membrane metabolism, signal transduction, protein $\mathrm{C}$ activation [6] and amyloid deposition [7]. We have previously reported [5] that subjects with DS who do not have dementia (DS-) have a significant increase in the concentration of $\mathrm{mI}$ as compared to controls, and that increased $\mathrm{mI}$ is associated with reduced overall cognitive ability (including memory). People with DS and dementia (DS+) have higher $\mathrm{mI}$ concentration than those without dementia (DS-), or people from the general population who have AD or mild cognitive impairment $[8,9]$.

These DS-specific vulnerability factors may also combine with the additional burden of having a lower cognitive reserve due to pre-existing intellectual disability. The concept of brain reserve refers to the ability of the brain to tolerate the pathology of age- and disease-related changes without obvious clinical evidence [10]. The greater the reserve, the more severe pathological changes are needed to cause clinically functional impairment [10-12]. The cognitive reserve model suggests that the brain actively attempts to cope with brain damage by using preexisting cognitive processing approaches or by enlisting compensatory ones [11].

Greater cognitive reserve can arise through numerous mechanisms, but is generally greater in people with higher overall intelligence, and/or those able to more efficiently/ flexibly use brain networks [13]. Dementia risk has repeatedly been reported to be much lower in high-reserve individuals, but much higher in people with limited education and/or intellectual disability - a finding replicated across more than 20 studies involving more than 29,000 individuals and over a median follow-up period of greater than seven years [14]. Hence, it may be that dementia in people with DS is associated with less loss of brain tissue than in the general population because they have less cognitive reserve, due perhaps to a double hit of pre-existing intellectual disability combined with a genetically determined increase in risk factors such as brain amyloid and $\mathrm{mI}$ concentration.

In the general population, $\mathrm{AD}$ is associated with a loss of brain tissue, including from the temporal lobe and hippocampus [15-24], and the expansion of cerebrospinal fluid (CSF) [17,22,25-31]. Furthermore, AD severity is associated with progressive brain atrophy [32]. In comparison, there are relatively few magnetic resonance imaging (MRI) studies of dementia in DS. Nevertheless those that are available have reported that compared to DS-, DS+ have a significant reduction in the volume of the medial temporal lobe/hippocampus [33-35], in addition to a significant reduction in the volume of the whole brain and/ or an increase in the volume of CSF $[33,34,36]$.

To our knowledge, no in vivo case-control study has yet compared the anatomy of dementia in DS to people with
$\mathrm{AD}$ in the general population. Therefore, we compared the volume of whole brain matter, lateral ventricles, temporal lobes and hippocampus in DS+ and DS- to each other, and to three non-DS groups. These included one group of individuals with $\mathrm{AD}$ and two groups of controls (each agematched for their respective DS and general population $\mathrm{AD}$ cohorts). We tested the hypotheses that: (1) people with dementia (in both DS and in the general population) have a significant reduction in the volume of whole brain, temporal lobe and hippocampus and an increase in the volume of the lateral ventricles compared with controls, and (2) people with dementia and DS have less brain atrophy than people with $\mathrm{AD}$ in the general population.

\section{Method}

\section{Participants}

We included a total of 192 adults with successful MRI brain scans: 64 individuals with DS (19 DS+ and 45 DS-) and 128 adults without DS (43 younger healthy control subjects age-appropriate to the DS sample; and 46 older people with $\mathrm{AD}$, together with 39 older healthy control subjects age-appropriate to the AD sample).

Individuals with genetically confirmed DS were recruited from community centres, residential homes and speciality clinics in London, Birmingham, Plymouth and Newcastle upon Tyne, UK. DS status was assessed in all participants by karyotyping and cognitive status was measured using the Cambridge Cognitive Examination (CAMCOG), a composite index of episodic memory, orientation, language, attention, praxis and executive function previously validated for use in DS [37]. The CAMCOG is appropriate for assessing cognitive function in people with intellectual disability, unlike more standard tests of cognitive function such as the Wechsler Adult Intelligence Scales. The CAMCOG incorporates, and is highly correlated with, the Mini Mental State Examination (MMSE) [38]. The decline in function of DS+ was based on the International Classification of Diseases-10 (ICD-10) Research Diagnostic Criteria. The $\mathrm{AD}$ samples were part of a larger, national longitudinal study based at the Institute of Psychiatry, London. Individuals from this study were diagnosed with dementia using the ICD-10 Research Diagnostic Criteria, with non-AD dementia excluded, in keeping with the $\mathrm{Na}$ tional Institute of Neurological and Communicative Disorders and Stroke and Alzheimer's Disease and Related Disorders Association (NINCDS-ADRDA) Criteria [14]. Age-appropriate, healthy controls $(\mathrm{HC})$ were recruited from general practice lists and the local population as part of both studies. Absence of dementia was confirmed by screening with the CAMCOG and the MMSE.

All participants underwent standard physical, neurological and psychiatric screening, including routine clinical blood tests (for example, renal, liver and thyroid function). In addition, all participants underwent clinical MRI to 
exclude other brain disorders, including stroke or vascular dementia. Exclusion criteria included the presence of detectable physical disorder (for example, history of birth trauma or head injury), psychiatric illness (for example, major depression or psychosis) or other reason for cognitive decline (for example, changes in living situation). None of the participants were taking antipsychotic or antidepressant medication at the time of the study. However, seven DS+ (37\%) and $25 \mathrm{AD}(54 \%)$ participants were taking acetylcholinesterase (AChE) inhibitors.

It should be noted that we had a very high success rate in MRI scanning in our DS+ and AD groups, with less than $20 \%$ dropout/non-compliance across all recruited participants with dementia. There were no significant differences in age, gender, number of years in education or cognitive status between the dropouts and those from whom it was possible to obtain a successful scan. The study was approved by local and national Ethics Committees. After a complete description of the study was provided to the participant and the identified carer, written informed consent was obtained where possible. Where not possible, the participant's assent was obtained with formal consent provided by an identified carer.

\section{MRI protocol}

Subjects were scanned using a 1.5 Tesla, GE NV/i Signa MR system at the Maudsley Hospital, London. A vacuum fixation device ensured that subjects were both comfortable and restrained from movement during the scanning process. The whole brain was imaged with threedimensional inversion recovery prepared fast spoiled gradient-recalled acquisition in the steady state (SPGR) T1-weighted dataset. These T1-weighted images were obtained in the axial plane with $1.5-\mathrm{mm}$ contiguous sections, repetition time (TR) of 13.8 milliseconds, inversion time (TI) of 450 milliseconds, echo time (TE) of 2.8 milliseconds and flip angle of $20^{\circ}$ with one data average and a $256 \times 256 \times 124$ matrix. Image contrast for all datasets was chosen with the aid of optimising software [39]. Acquisition time was 6 minutes, 27 seconds. Full brain and skull coverage was required and a detailed quality control was carried out on all MR images according to previously described quality control procedures $[40,41]$.

\section{MRI data analysis}

Volumetric analysis of hippocampi, temporal lobes, lateral ventricles, whole brain matter and total intracranial volumes (TIV) were performed. Manual tracing was performed on SPGR data sets using both Measure Image Analysis Software [42,43] (Johns Hopkins University, Baltimore, Maryland, USA) and published anatomical definitions $[43,44]$. Whole brain matter volume consisted of total cerebral hemispheres (frontal, temporal, parietal and occipital lobes) and excluded lateral and third ventricles.
The three-dimensional acquisition as utilised, well differentiated brain parenchyma from CSF (including peripheral CSF, lateral and third ventricles) and was based upon differences in pixel intensities in signal as derived from the T1 weighted sequences employed. Intracranial volume included all brain matter (cerebral hemispheres, cerebellum and brainstem) lateral and third ventricles and all peripheral CSF in the cranium. The extra axial boundaries were derived from analysis of the signal of the dura and diploic space, permitting identification of the subdural contents. At the base of the brain, the dural signal line was carefully followed and where there was any interruption in this signal, raters utilised their knowledge of neuroanatomy to estimate the line best connecting the dural signal. The temporal lobes included all pixels traced from the anterior pole of the temporal lobe to the aqueduct of Sylvius with the superior temporal lobe boundary defined as a straight line drawn from the angle of the medial temporal lobe, where it was attached to the temporal stem, to the midpoint of the operculum. The dura of the middle cranial fossa was then traced around each temporal lobe to complete the temporal lobe region [44]. The hippocampus was traced by means of an adaptation of the criteria of Watson et al. [45] - namely, we did not trace the hippocampus any further than the aqueduct of Sylvius. The superior and inferior horns of the lateral ventricles were measured from their first appearance in the frontal and temporal lobes, respectively, terminating at the atrium. The posterior horn of the lateral ventricles was measured from the atrium to its last appearance (on the coronal slice) in the occipital lobe. Raters were blind to subject status. The volume of each region was calculated by multiplying the summed pixel cross-sectional areas by slice thickness. Intra-rater and inter-rater reliabilities were determined for the brain regions of interest (ROIs) traced by the operators as part of this analysis. Inter-rater reliabilities were obtained for all regions traced [46]. The intrarater and inter-rater reliabilities were intraclass correlation coefficients. For all regions $r$ was $>0.9$ for the inter-and intra-rater correlation coefficients.

In order to control for the relationship between brain volume and head size, volumes were expressed as raw (uncorrected) volumes, and when normalised, as a percentage of traced TIV. Statistical analyses were carried out on both raw and corrected brain volumes. TIV is determined during childhood by the volume of brain, meninges, and CSF contained within it $[47,48]$. Brain volume is maximal by early childhood and appears to decline from early adulthood. The normalisation to TIV provided the proportion of hippocampal volume to past brain size.

\section{Statistical analysis}

Subject groups were normally distributed. All volumes were normally distributed and were analysed using 
univariate analysis. However, age was significantly different between groups (F 157.556, $P<0.001$ ), as was the gender distribution. Age, gender and TIV were added as covariates in the analysis. CAMCOG scores were corrected for age. Follow-up pairwise comparisons among estimated marginal means, adjusting for covariates, were conducted where appropriate. Pairwise analyses were adjusted for multiple tests. All significance tests used a $P$-value of $<0.05$ adjusted for multiple testing using the Bonferroni correction. The percentage reduction in the volume of the raw and TIV-corrected volumes of the hippocampus and temporal lobe (and the percentage increase in the volume of the lateral ventricles) within individuals with DS between DS+ and DS-, were compared to those within AD cases and controls from the general population by means of the $t$-test. The percentage differences were based on agecorrected volumes. Our results may have been confounded by medication status, therefore, we compared brain anatomy in individuals with dementia who were taking AChE inhibitors and those who were not taking such medication.

\section{Results (Table 1)}

\section{Raw (uncorrected) volumes}

There was a significant main effect of group for the hippocampus, temporal lobes and lateral ventricles. There was a significant main effect of group and gender for whole brain volume (WBV) and TIV. We found no significant differences between DS+ who were taking AChE inhibitors and those who were not.

Follow-up pairwise comparisons revealed that compared to their respective control groups without dementia, both DS+ and AD had a highly significant reduction in the volume of the hippocampus, and AD (but not DS+) had a highly significant reduction in the volume of the temporal lobe and a highly significant increase in the volume of the lateral ventricles. DS+ had a highly significant reduction in the volume of the hippocampus compared to DS-. Compared to the DS healthy control group (the younger healthy control group), both DS+ and DS- had a highly significant reduction in WBV (Figure 1). The hippocampal and temporal lobe volume reductions in $\mathrm{AD}$ and $\mathrm{DS}+$ were disproportionately greater than the WBV reduction.

The percentage differences between DS+ and DS-, were compared to those within AD cases and controls from the general population and were found to be significant. The reduction in the volume of the hippocampus between DS+ and DS- was similar to that within AD cases and controls from the general population ( $19 \%$ and $17 \%$, respectively). In contrast, the reduction in the volume of the temporal lobe between DS+ and DS- was almost twice that within $\mathrm{AD}$ cases and controls from the general population (14\% and $8 \%$, respectively). The increase in volume of the lateral ventricles between DS+ and DS- was less than that within
$\mathrm{AD}$ cases and controls from the general population (36\% and $43 \%$ respectively).

\section{Volumes corrected for TIV}

There was a significant main effect of group for the hippocampus, temporal lobes and the lateral ventricles. There was a significant main effect of gender for the temporal lobe. Follow-up pairwise comparisons revealed that compared to their respective control groups without dementia, both DS+ and AD had a highly significant reduction in the volume of the hippocampus (Figure 2), and AD (but not DS+) had a highly significant reduction in the volume of the temporal lobe (Figure 3 ) and a highly significant increase in the volume of the lateral ventricles (Figure 4). DS+ had a highly significant reduction in the volume of the hippocampus compared to DS-.

The percentage differences between DS+ and DS-, were compared to those within $\mathrm{AD}$ cases and controls from the general population and were found to be significant. The reduction in the volume of the hippocampus between DS+ and DS- was less than half that within AD cases and controls from the general population $(7 \%$ and $15 \%$ respectively). Similarly, the reduction in the volume of the temporal lobe between DS+ and DS- was also less than half that within $\mathrm{AD}$ cases and controls from the general population ( $2 \%$ and $5 \%$, respectively). The increase in volume of the lateral ventricles between DS+ and DS- was similar to that between AD and AD HC (41\% and 40\%, respectively).

\section{Relationship of cognitive ability to brain anatomy}

In the $\mathrm{AD}$ population, there was a positive correlation between MMSE and corrected hippocampal volume $(r=$ $0.311, P=0.01)$ and between MMSE and corrected temporal lobe volume $(r=0.316, P=0.05)$. There was a negative correlation between MMSE and the corrected lateral ventricle volume $(r=-0.475, P=0.01)$. The $\mathrm{DS}+$ population showed a positive correlation between CAMCOG and the corrected hippocampal volume $(r=0.216, P=$ $0.05)$ and between CAMCOG and the corrected temporal lobe volume $(r=0.435, P=0.01)$. There was a negative correlation between MMSE and the corrected lateral ventricle volume $(r=-0.462, P=0.01)$.

\section{Discussion}

In this study, we found that people with dementia (both with $\mathrm{DS}$ and $\mathrm{AD}$ ) had a reduction in the volume of whole brain, temporal lobe and hippocampus, in addition to an elevation in lateral ventricle volume, compared to controls. Also, for the first time, we found that DS+ had a relatively smaller reduction in brain volume compared to people with $\mathrm{AD}$ in the general population. Following normalisation and correction for confounders, it was found that both the $\mathrm{AD}$ and $\mathrm{DS}+$ groups had a significant 
Table 1 Magnetic resonance imaging comparing subjects with Down's syndrome and Alzheimer's disease in the general population

\begin{tabular}{|c|c|c|c|c|c|c|c|c|}
\hline & $\begin{array}{l}D S+(n=19) \\
\text { mean } \pm S D\end{array}$ & $\begin{array}{l}\text { DS- }(n=45) \\
\text { mean } \pm \text { SD }\end{array}$ & $\begin{array}{l}\mathrm{DS} \mathrm{HC}(n=43) \\
\text { mean } \pm \text { SD }\end{array}$ & $\begin{array}{l}A D(n=46) \\
\text { mean } \pm S D\end{array}$ & $\begin{array}{l}A D H C \text { mean } \\
\pm S D\end{array}$ & $\begin{array}{l}\text { F effect of group } \\
\text { ( } P \text {-value) }\end{array}$ & $\begin{array}{l}\text { F effect of gender } \\
\text { (P-value) }\end{array}$ & $\begin{array}{l}\text { Significant pairwise } \\
\text { comparisons }\end{array}$ \\
\hline Age (years) ${ }^{*}$ & $51.52 \pm 7.89$ & $38.07 \pm 12.24$ & $33.75 \pm 11.37$ & $76.59 \pm 5.3$ & $75.87 \pm 5.53$ & $157.556(<0.001)$ & NS & $\begin{array}{l}\mathrm{DS}+<\mathrm{AD} ; \mathrm{DS}+<\mathrm{AD} H \mathrm{HC} ; \mathrm{DS}-<\mathrm{AD} ; \\
\mathrm{DS}-<\mathrm{DS}+\text {; DS HC<AD; DS HC<DS } \\
+; \mathrm{DS} H C<\mathrm{AD} \mathrm{HC}\end{array}$ \\
\hline Education (years) & & & & $11.13 \pm 3.22$ & $11.49 \pm 3$ & NS & NS & NS \\
\hline Sex (female:male) & 10:9 & 31:14 & 29:14 & $22: 24$ & 11:28 & & & \\
\hline MMSE $^{*}$ & $9.32 \pm 4.46$ & $13.88 \pm 5.56$ & $15.23 \pm 2.53$ & $22.48 \pm 3.74$ & $28.74 \pm 3.23$ & $35.757(<0.001)$ & NS & $\begin{array}{l}A D<A D H C ; D S+<A D ; D S+<A D \\
H C ; D S-<A D ; D S-<A D H C ; D S \\
H C<A D ; D S H C<A D H C\end{array}$ \\
\hline CAMCOG $^{*}$ & $33.72 \pm 19.77$ & $52.98 \pm 21.48$ & $114.83 \pm 16.52$ & & & $59.323(<0.001)$ & NS & $\mathrm{DS}+<\mathrm{DS} H \mathrm{HC} ; \mathrm{DS}-<\mathrm{DS} H C$ \\
\hline $\begin{array}{l}\text { Whole brain } \\
\text { volume (WBV, ml) }\end{array}$ & $836.33 \pm 98.72$ & $961.96 \pm 111.16$ & $1100 \pm 101.23$ & $904.32 \pm 83.3$ & $930.77 \pm 77.41$ & $23.296(<0.001)$ & $28.717(<0.001)$ & $\begin{array}{l}\mathrm{DS}+<\mathrm{AD} ; \mathrm{DS}+<\mathrm{AD} H \mathrm{HC} ; \mathrm{DS}+<\mathrm{DS} \\
\mathrm{HC} ; \mathrm{DS}-<\mathrm{AD} \mathrm{HC} ; \mathrm{DS}-<\mathrm{DS} H C ; \mathrm{DS} \\
+<\mathrm{DS}-\end{array}$ \\
\hline $\begin{array}{l}\text { Total intracranial } \\
\text { volume (TIV, ml) }\end{array}$ & $1096.46 \pm 97.76$ & $1195.7 \pm 120.08$ & $1387.95 \pm 125.08$ & $1292.39 \pm 109.27$ & $1277.27 \pm 97.95$ & $38.112(<0.001)$ & $55.296(<0.001)$ & $\begin{array}{l}\mathrm{DS}+<\mathrm{AD} ; \mathrm{DS}+<\mathrm{AD} H \mathrm{HC} ; \mathrm{DS}+<\mathrm{DS} \\
\mathrm{HC} ; \mathrm{DS}-<\mathrm{AD} ; \mathrm{DS}-<\mathrm{AD} H C ; \mathrm{DS}-<\mathrm{DS} \\
\mathrm{HC}\end{array}$ \\
\hline Hippocampus (ml) & $4.52 \pm 1.06$ & $5.56 \pm 0.81$ & $6.82 \pm 0.62$ & $5.13 \pm 1.04$ & $6.19 \pm 0.85$ & $13.242(<0.001)$ & NS & $\begin{array}{l}\mathrm{AD}<\mathrm{AD} H \mathrm{HC} ; \mathrm{AD}<\mathrm{DS} H \mathrm{HC} ; \mathrm{DS}+<\mathrm{DS}-; \\
\mathrm{DS}+<\mathrm{AD} H \mathrm{HC} ; \mathrm{DS}+<\mathrm{DS} H C ; \text { DS- } \\
<\mathrm{DS} H C\end{array}$ \\
\hline $\begin{array}{l}\text { Hippocampal } \\
\text { volume normalised } \\
\text { by TIV (\% TIV })^{*}\end{array}$ & $0.41 \pm 0.09$ & $0.47 \pm 0.07$ & $0.49 \pm 0.05$ & $0.4 \pm 0.07$ & $0.5 \pm 0.06$ & $13.095(<0 . .001)$ & NS & $\begin{array}{l}\mathrm{AD}<\mathrm{DS} H \mathrm{HC} ; \mathrm{AD}<\mathrm{AD} H \mathrm{HC} ; \mathrm{DS}+<\mathrm{DS}-; \\
\mathrm{DS}+<\mathrm{AD} \mathrm{HC} ; \mathrm{DS}+<\mathrm{DS} H \mathrm{HC}\end{array}$ \\
\hline $\begin{array}{l}\text { Left hippocampus } \\
(\mathrm{ml})^{*}\end{array}$ & $2.37 \pm 0.58$ & $2.97 \pm 0.59$ & $3.52 \pm 0.38$ & $2.62 \pm 0.51$ & $3.17 \pm 0.46$ & $12.723(<0.001)$ & NS & $\begin{array}{l}\mathrm{AD}<\mathrm{AD} \mathrm{HC} ; \mathrm{AD}<\mathrm{DS} H \mathrm{HC} ; \mathrm{DS}+<\mathrm{DS} \\
\mathrm{HC} ; \mathrm{DS}-<\mathrm{DS} H \mathrm{C}\end{array}$ \\
\hline $\begin{array}{l}\text { Left hippocampus } \\
\text { normalised by TIV } \\
\text { (\% TIV)* }\end{array}$ & $0.22 \pm 0.05$ & $0.24 \pm 0.03$ & $0.25 \pm 0.03$ & $0.2 \pm 0.03$ & $0.25 \pm 0.03$ & $12.339(<0.001)$ & NS & $\begin{array}{l}\mathrm{AD}<\mathrm{DS}-; \mathrm{AD}<\mathrm{AD} H \mathrm{HC} ; \mathrm{AD}<\mathrm{DS} H \mathrm{HC} ; \\
\mathrm{DS}+<\mathrm{DS} \mathrm{HC} ; \mathrm{DS}+<\mathrm{DS}-\end{array}$ \\
\hline $\begin{array}{l}\text { Right hippocampus } \\
(\mathrm{ml})^{* *}\end{array}$ & $2.16 \pm 0.52$ & $2.7 \pm 0.47$ & $3.31 \pm 0.31$ & $2.48 \pm 0.58$ & $3.02 \pm 0.44$ & $11.540(<0.001)$ & NS & $\begin{array}{l}\mathrm{AD}<\mathrm{AD} H \mathrm{HC} ; \mathrm{AD}<\mathrm{DS} \mathrm{HC} ; \mathrm{DS}+<\mathrm{DS} \\
\mathrm{HC} ; \mathrm{DS}+<\mathrm{AD} H C ; \mathrm{DS}+<\mathrm{DS}-\end{array}$ \\
\hline $\begin{array}{l}\text { Right hippocampus } \\
\text { normalised by TIV } \\
\left(\% \text { TIV}^{*}\right.\end{array}$ & $0.2 \pm 0.04$ & $0.23 \pm 0.04$ & $0.24 \pm 0.03$ & $0.19 \pm 0.04$ & $0.24 \pm 0.03$ & $11.660(<0.001)$ & NS & $\begin{array}{l}\mathrm{AD}<\mathrm{AD} H C ; \mathrm{AD}<\mathrm{DS} H C ; \mathrm{DS}+<\mathrm{AD} \\
\mathrm{HC} ; \mathrm{DS}+<\mathrm{DS} \mathrm{HC} ; \mathrm{DS}+<\mathrm{DS}-\end{array}$ \\
\hline $\begin{array}{l}\text { Temporal lobes } \\
(\mathrm{ml})^{*}\end{array}$ & $104.23 \pm 16.84$ & $121.75 \pm 14.95$ & $136.16 \pm 16.65$ & $101.78 \pm 15$ & $110.57 \pm 14.21$ & $5.947(<0.001)$ & NS & $A D<D S-; A D<A D H C$ \\
\hline $\begin{array}{l}\text { Temporal lobes } \\
\text { normalised by TIV } \\
\text { (\% TIV)* }\end{array}$ & $9.48 \pm 1.1$ & $10.2 \pm 0.93$ & $9.8 \pm 0.77$ & $7.86 \pm 0.81$ & $8.65 \pm 0.8$ & $5.998(<0.001)$ & $4.2(0.042)$ & $A D<D S-; A D<A D H C$ \\
\hline $\begin{array}{l}\text { Left temporal lobe } \\
(\mathrm{ml})^{*}\end{array}$ & $52.05 \pm 8.55$ & $61.26 \pm 7.68$ & $68.72 \pm 8.15$ & $51.97 \pm 8.35$ & $56.74 \pm 9.61$ & $4.967(0.001)$ & NS & $A D<A D H C ; A D<D S-$ \\
\hline
\end{tabular}


Table 1 Magnetic resonance imaging comparing subjects with Down's syndrome and Alzheimer's disease in the general population (Continued)

\begin{tabular}{|c|c|c|c|c|c|c|c|c|}
\hline $\begin{array}{l}\text { Left temporal lobe } \\
\text { normalised by TIV } \\
(\% \text { TIV })^{* *}\end{array}$ & $4.73 \pm 0.57$ & $5.12 \pm 0.48$ & $4.95 \pm 0.4$ & $4.02 \pm 0.51$ & $4.43 \pm 0.58$ & $4.851(0.001)$ & NS & $A D<A D H C ; A D<D S-$ \\
\hline $\begin{array}{l}\text { Right temporal } \\
\text { lobe }(\mathrm{ml})^{* *}\end{array}$ & $52.17 \pm 8.7$ & $60.02 \pm 7.81$ & $67.37 \pm 9.63$ & $49.8 \pm 9.14$ & $53.82 \pm 7.21$ & $3.067(0.018)$ & NS & $A D<A D H C$ \\
\hline $\begin{array}{l}\text { Right temporal } \\
\text { lobe normalised by } \\
\text { TIV (\% TIV) }\end{array}$ & $4.74 \pm 0.54$ & $5.0 \pm 0.57$ & $4.85 \pm 0.49$ & $3.84 \pm 0.57$ & $4.22 \pm 0.51$ & $3.112(0.017)$ & NS & $A D<A D H C$ \\
\hline $\begin{array}{l}\text { Lateral ventricles } \\
(\mathrm{ml})^{*}\end{array}$ & $26.78 \pm 21.32$ & $17.21 \pm 15.94$ & $10.56 \pm 8.38$ & $49 \pm 21.81$ & $27.72 \pm 12.27$ & $9.238(<0.001)$ & NS & $A D>A D H C ; A D>D S H C$ \\
\hline $\begin{array}{l}\text { Lateral ventricles } \\
\text { normalised by TIV } \\
\left(\% \text { TIV}^{*}\right.\end{array}$ & $2.44 \pm 1.86$ & $1.43 \pm 1.24$ & $0.76 \pm 0.61$ & $3.8 \pm 1.65$ & $2.16 \pm 0.89$ & $9.009(<0.001)$ & NS & $A D>A D H C ; A D>D S H C$ \\
\hline $\begin{array}{l}\text { Left lateral ventricle } \\
(\mathrm{ml})^{*}\end{array}$ & $12.7 \pm 12.08$ & $7.52 \pm 6.47$ & $5.26 \pm 4.36$ & $22.68 \pm 10.75$ & $13.6 \pm 6.07$ & $7.115(<0.001)$ & NS & $A D>A D H C ; A D>D S H C$ \\
\hline $\begin{array}{l}\text { Left lateral ventricle } \\
\text { normalised by TIV } \\
\left(\% \text { TIV }^{*}\right.\end{array}$ & $1.16 \pm 1.04$ & $0.63 \pm 0.51$ & $0.38 \pm 0.32$ & $1.76 \pm 0.82$ & $1.06 \pm 0.45$ & $6.967(<0.001)$ & NS & $A D>A D H C ; A D>D S H C$ \\
\hline $\begin{array}{l}\text { Right lateral } \\
\text { ventricle }(\mathrm{ml})^{* *}\end{array}$ & $14 \pm 9.69$ & $9.66 \pm 9.58$ & $5.3 \pm 4.36$ & $26.17 \pm 11.63$ & $14.11 \pm 6.7$ & $10.3(<0.001)$ & NS & $\begin{array}{l}A D>A D H C ; A D>D S H C ; D S+>D S \\
H C\end{array}$ \\
\hline $\begin{array}{l}\text { Right lateral } \\
\text { ventricle } \\
\text { normalised by TIV } \\
(\% \text { TIV) }\end{array}$ & $1.27 \pm 0.86$ & $0.8 \pm 0.7$ & $0.38 \pm 0.31$ & $2.0 \pm 0.88$ & $1.1 \pm 0.48$ & $9.995(<0.001)$ & NS & $\begin{array}{l}A D>A D H C ; A D>D S H C ; D S+>D S \\
H C\end{array}$ \\
\hline
\end{tabular}


reduction in hippocampal volume when compared to their comparison control groups. The AD group also showed a significant reduction in temporal lobe volume and a significant increase in lateral ventricle volume compared to its age-matched control group.

Subjects with DS are at an increased risk for dementia, thought to be of the AD type [47-49]. The hippocampal volumes in DS+ in this study were disproportionably small compared to age-matched healthy controls. This is in agreement with previous neuropathological [44] and neuroimaging studies of subjects with DS [32,33,50-52] and a number of MRI studies of AD subjects in the general population [23,24,53-55]. Reduced hippocampal volume however, is not a feature of all people with an intellectual disability. In subjects with fragile $\mathrm{X}$ syndrome [56] and autism [57], for example, corrected hippocampal volume is reported to be significantly increased compared to healthy controls. Therefore, reduced hippocampal volume in the brains of subjects with DS does not appear to simply reflect a non-specific effect of an intellectual disability.

In individuals with DS, the reduction in the volume of the hippocampus in DS+ compared to DS- was less than half that in people with $\mathrm{AD}$ compared to controls from the general population ( $7 \%$ and $15 \%$, respectively). Similarly, the reduction in the volume of the temporal lobe in DS+ compared to DS- was also less than half that in people with $\mathrm{AD}$ compared to controls from the general population ( $2 \%$ and $5 \%$, respectively). The conclusion that DS + subjects have less brain volume than $\mathrm{AD}$ subjects was therefore based on the TIV-corrected percentage differences between the hippocampus and temporal lobe volumes for DS+ versus DS-, as compared with AD versus AD HC. In this study DS- had a mean age of 38 years but did not show a significant difference from DS $\mathrm{HC}$ for the volumes of the lateral ventricle or for the lateral ventricle volume corrected for TIV. DS- in this study are very likely to develop dementia as they age.

In corroboration with our findings, a number of previous studies have demonstrated a reduction in the volume of the hippocampus in individuals with DS compared to healthy controls, utilising MRI [50,58,59]. Furthermore, DS- have also been shown to have smaller hippocampi compared to healthy controls [51], with an age-related reduction in hippocampal volume compared to controls also evident [60].

Post-mortem studies have reported that adults with DS have prominent neuropathology in the medial temporal lobe structures in the early stages of $\mathrm{AD}$ [61-64]. In the current study, the volumetric findings in subjects with DS were consistent with an AD pattern of atrophy, with a reduction in the volume of the hippocampus. This study tentatively supports the finding that the hippocampus is one of the brain regions most severely affected by amyloid plaques and neurofibrillary plaques in DS [63] and that a

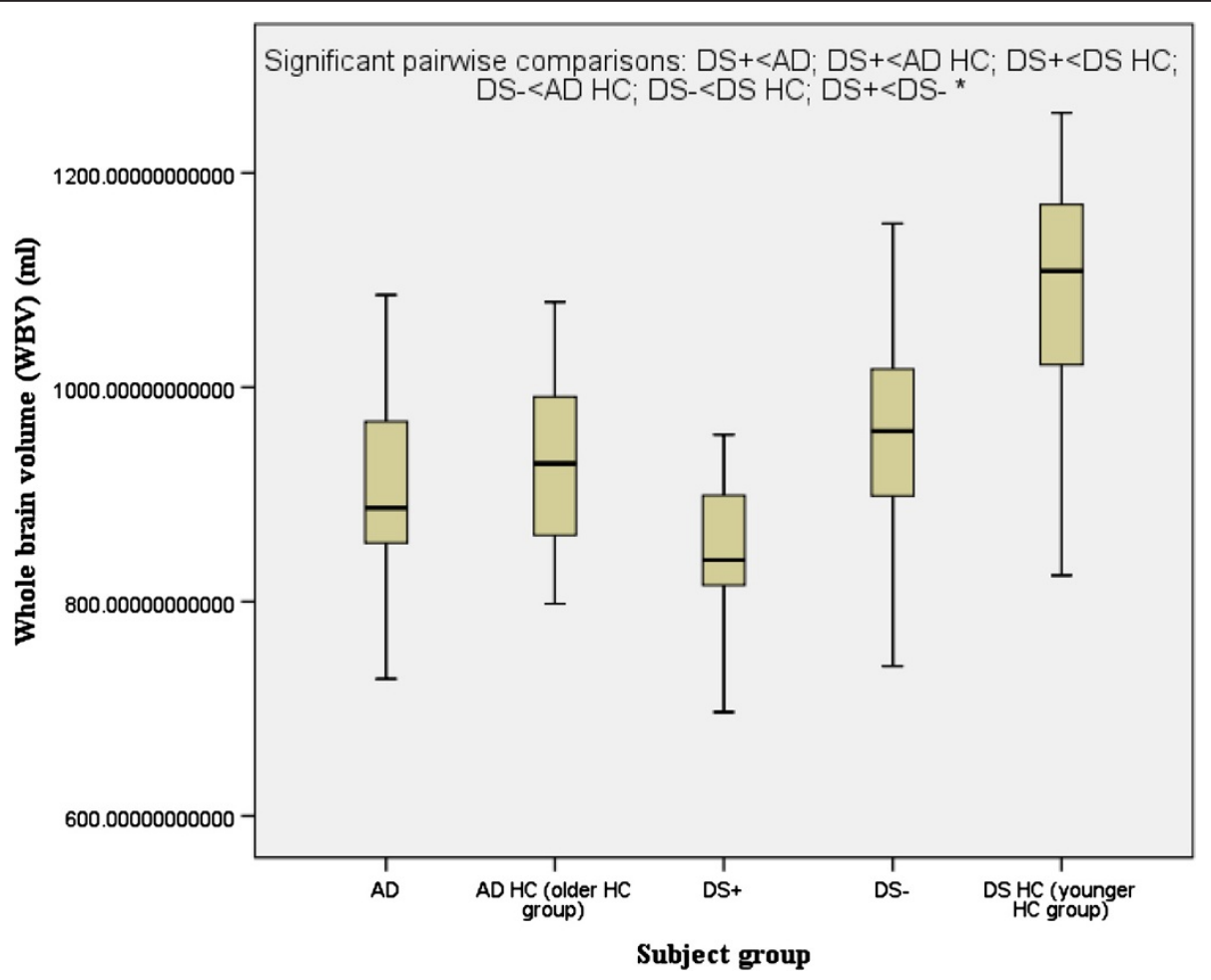

Figure 1 Whole brain volume. Comparison of people with Alzheimer's disease (AD) versus those with Down's syndrome and dementia (DS+). HC, healthy controls; DS-, people with Down's syndrome without dementia. ${ }^{*} \mathrm{P}<0.0001$. 


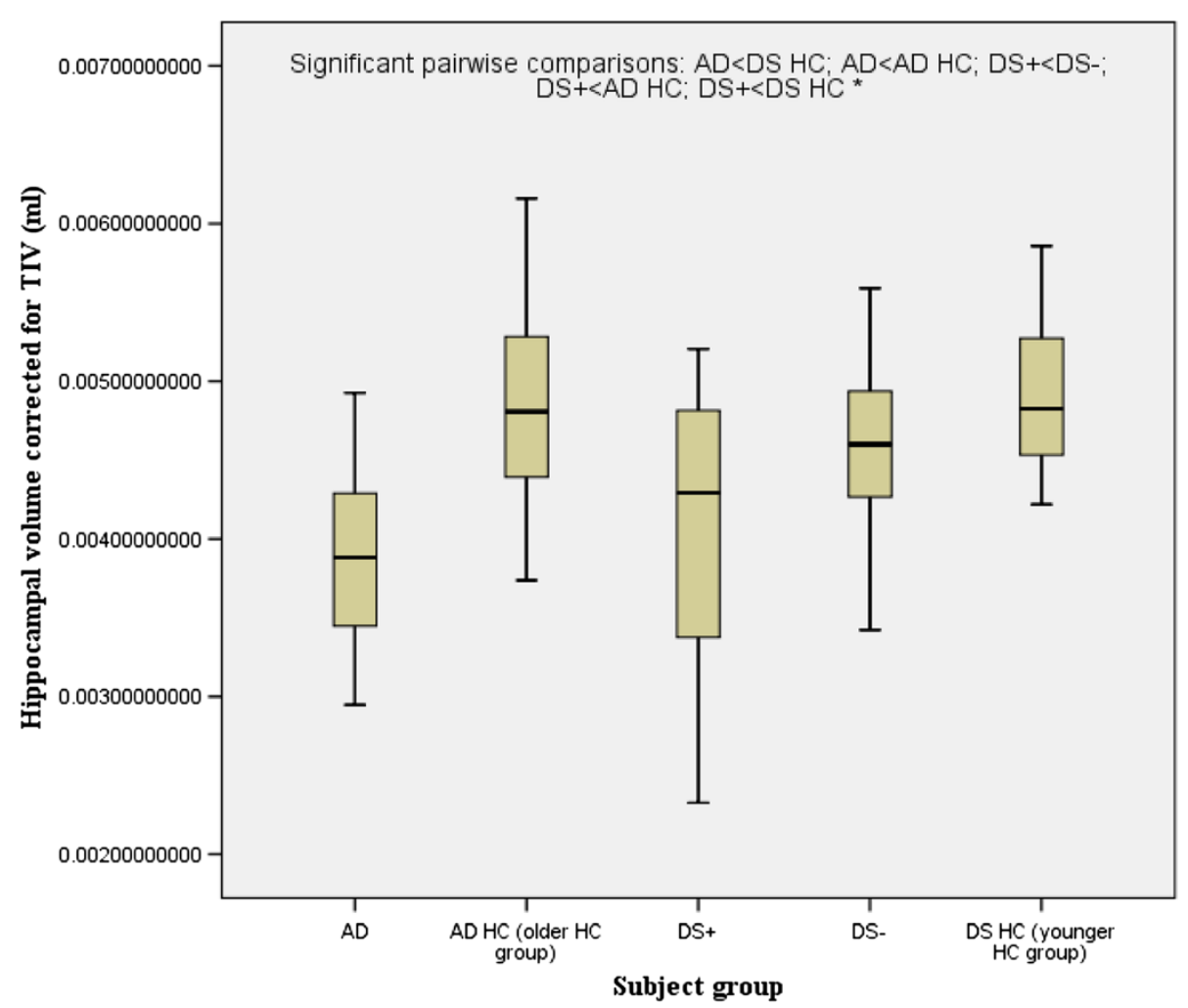

Figure 2 Hippocampal volume corrected for total intracranial volume (TIV) (corrected as a ratio of the hippocampal volume to TIV). Comparison of people with Alzheimer's disease (AD) and people with Down's syndrome with dementia (DS+). HC, healthy controls; DS-, people with Down's syndrome without dementia. ${ }^{*} \mathrm{P}<0.0001$.

reduction in hippocampal volume may provide a useful tool to assist the diagnosis of dementia in people with DS, as has been proposed for people with $\mathrm{AD}$ in the general population $[65,66]$.

The first volumetric MRI study of AD published in 1988 described a $40 \%$ reduction in the volume of the hippocampus of subjects with AD compared to HC [67]. Subsequent studies have similarly reported reduced volume of the hippocampal and parahippocampal formation in $\mathrm{AD}$ of $20 \%$ to $52 \%$ [68], with this volume reduction already present at the first stages of AD [69-71]. The results of the current study showed that in individuals with DS, the reduction in the volume of the hippocampus in DS+ compared to DS- was similar to that in people with $\mathrm{AD}$ compared to controls from the general population (19\% and $17 \%$, respectively). However, atrophy of the hippocampus is not specific to $\mathrm{AD}$ and occurs in other forms of dementia [72,73]. Despite this, hippocampal volume has been shown to be superior to clinical diagnosis or cognitive assessment in predicting AD neuropathology [74].

We demonstrated a reduction in temporal lobe volume in subjects with $\mathrm{AD}$ compared to their age-matched $\mathrm{HC}$, a finding consistent with previous MRI volumetric studies [75-80]. The medial temporal lobe plays an important role in the storage of new information $[81,82]$ and atrophy of the medial temporal lobe may explain why memory dysfunction is an early symptom of $\mathrm{AD}[83,84]$. Consistent with this, subjects with memory impairment who do not meet the criteria for dementia have an increased risk of subsequent AD [85-87]. In the same way, atrophy of the hippocampus increases the risk for subsequent $\mathrm{AD}$ in elderly individuals without dementia $[88,89]$ and for asymptomatic individuals at risk of autosomal dominant $\mathrm{AD}[90]$.

The cognitive-reserve hypothesis concerns the percentage of the brain that is occupied by the hippocampus. People with a greater proportion of their brains occupied by their hippocampus would therefore have an increased relative reserve. Individuals with higher levels of cognitive reserve will have a lower prevalence and incidence of dementia [91]. It is, therefore, a reduction in the volume of the hippocampus corrected by TIV (relative reserve) rather than a lack of raw hippocampal volume (reserve based on actual tissue volume) that makes one more susceptible to dementia. In the current study, follow-up pairwise comparisons revealed that compared to their respective control groups without dementia, both DS+ and people with $\mathrm{AD}$ had a highly significant reduction in the volume of the hippocampus, which had been corrected for TIV. 
It has been hypothesised that in the brain of people with DS, the presence of an extra copy of the amyloid precursor gene located on chromosome 21 leads to abnormalities in APP-processing in neuronal membranes, and subsequently to amyloid plaques and DS [3] However, mI also promotes the formation of amyloid plaques [7]. The cause of the elevation in $\mathrm{mI}$ concentration in the brain in DS and how this affects cognitive ability is unknown [5]. It is possible that the increase in $\mathrm{mI}$ concentration does not directly affect hippocampal neuronal function but simply reflects another underlying metabolic process that is more closely linked with neuronal dysfunction [5]. Therefore, the predisposition of people with DS to amyloid deposition and subsequent $\mathrm{AD}$ may arise from a significantly higher gene dose of both the APP and the mI transport genes [5].

A higher level of cognitive functioning has been shown to be associated with fewer cases of dementia in individuals with DS, and the level of cognitive functioning appears to be associated with environmental factors such as the level of education, years in an institution and employment [92]. Furthermore, individuals with lower levels of intellectual functioning are expected to experience an earlier onset of dementia symptoms and a faster rate of decline [92]. In addition, people with DS may develop symptoms of $\mathrm{AD}$ earlier in life than other individuals because of their smaller cognitive reserve and their increased production of amyloid beta. Hence it may be that dementia in people with DS can occur with less loss of brain tissue than in the general population because they have less cognitive reserve due perhaps to a double hit of pre-existing intellectual disability combined with a genetically determined increase in risk factors such as brain amyloid and $\mathrm{mI}$ concentration.

\section{Relationship of cognitive ability to brain anatomy}

The results of this study showed hippocampal and temporal lobe volume reductions in $\mathrm{AD}$ and $\mathrm{DS}+$, with these volume reductions correlated with cognitive decline in both groups. A positive correlation was demonstrated in the AD group for MMSE score and for both corrected hippocampal volume and corrected temporal lobe volume. This finding is corroborated by previous research also demonstrating that performance on the MMSE was directly correlated with hippocampal volume [61]. The correlation between MMSE and the volume in these critical areas, suggests that the function of the hippocampus and temporal lobe is compromised when the volume is reduced. One may thus speculate that severe medial temporal lobe atrophy is associated with greater cognitive decline, a proposal in line with the finding that a small

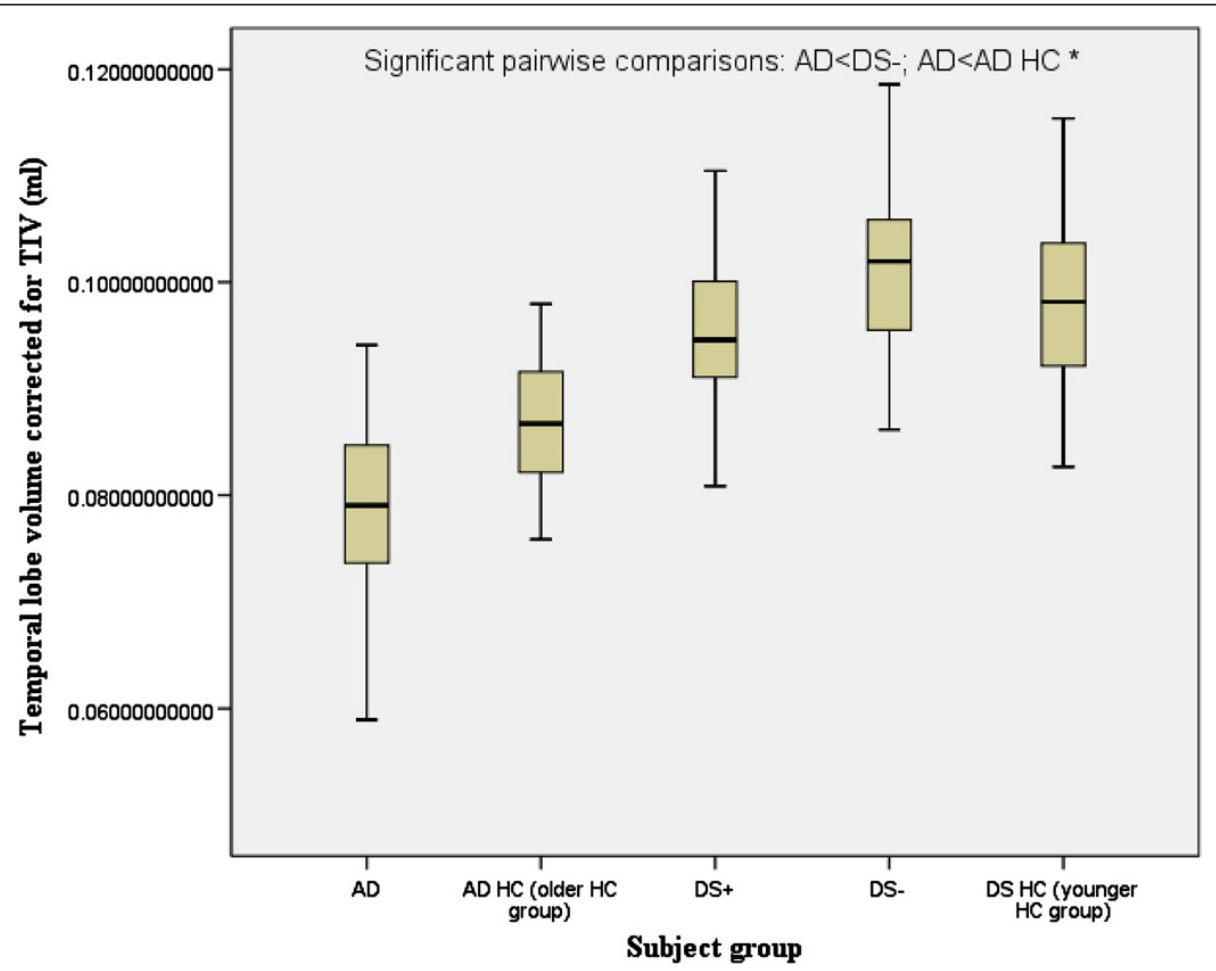

Figure 3 Temporal lobe volume corrected for total intracranial volume (TIV) (corrected as a ratio of the temporal lobe volume to TIV). Comparison of people with Alzheimer's disease (AD) and people with Down's syndrome with dementia (DS+). HC, healthy controls; DS-, people with Down's syndrome without dementia. ${ }^{*} \mathrm{P}<0.0001$. 
hippocampal volume at baseline is associated with a decrease in cognitive scores during follow up [93].

\section{Limitations}

The initial findings that people with dementia (both with DS and $\mathrm{AD}$ ) had a reduction in the volume of whole brain, temporal lobe and hippocampus; in addition to an elevation in lateral ventricle volume, compared to controls, were potentially confounded by significant between-group differences in brain size, age and gender. To overcome the potential confounder of brain size, all volumes were corrected for TIV.

Age was significantly different between the groups and is a confounder because age-related reductions in medial temporal brain regions, including the hippocampus, have previously been demonstrated in DS $[32,58,94,95]$. While all study groups ideally would be equivalent in age, including $\mathrm{AD}$ and $\mathrm{DS}+$, this is virtually impossible in this study. Life expectancy estimates suggest that only $14 \%$ of the DS population (with dementia or otherwise) reach the age of 68 years [96]. Furthermore, the neuropathology of AD and some degree of the gross neuroanatomical change associated with $\mathrm{AD}$ have been reported to occur in the brains of $80 \%$ of individuals with DS by the fourth decade and of $100 \%$ over 60 years of age [2]. Therefore, attaining DSand in particular DS+ groups over 65 years to match AD and control groups over 65 years of age, is not feasible. Thus, unlike some previous MRI studies [32,33] we covaried for age. We also corrected for gender as there was a higher proportion of female subjects in the AD HC group, and because gender is associated with differential degrees of brain volume reduction, including hippocampal volume reduction, with aging [44].

Another possible confounder for our results is that some DS individuals were taking AChE inhibitors and others were not. The reasons for this discrepancy are unknown, but it most probably reflects differences in local prescribing habits. We cannot state whether or not medication status in our DS+ and AD sample was related to length of illness. This is because it is often difficult to accurately access the date of onset of dementia in people with DS, and we were not able to retrospectively establish the time of $\mathrm{AD}$ onset or the length of illness. We found no significant differences between those participants with dementia who were taking $\mathrm{AChE}$ inhibitors and those who were not. Nonetheless, it remains possible that medication status was a significant confounder for our analysis. However, many DS+ are treated with AChE inhibitors and, therefore, we decided not to exclude these participants.

This was a cross-sectional study and clinical rather than post-mortem criteria were used to identify subjects with

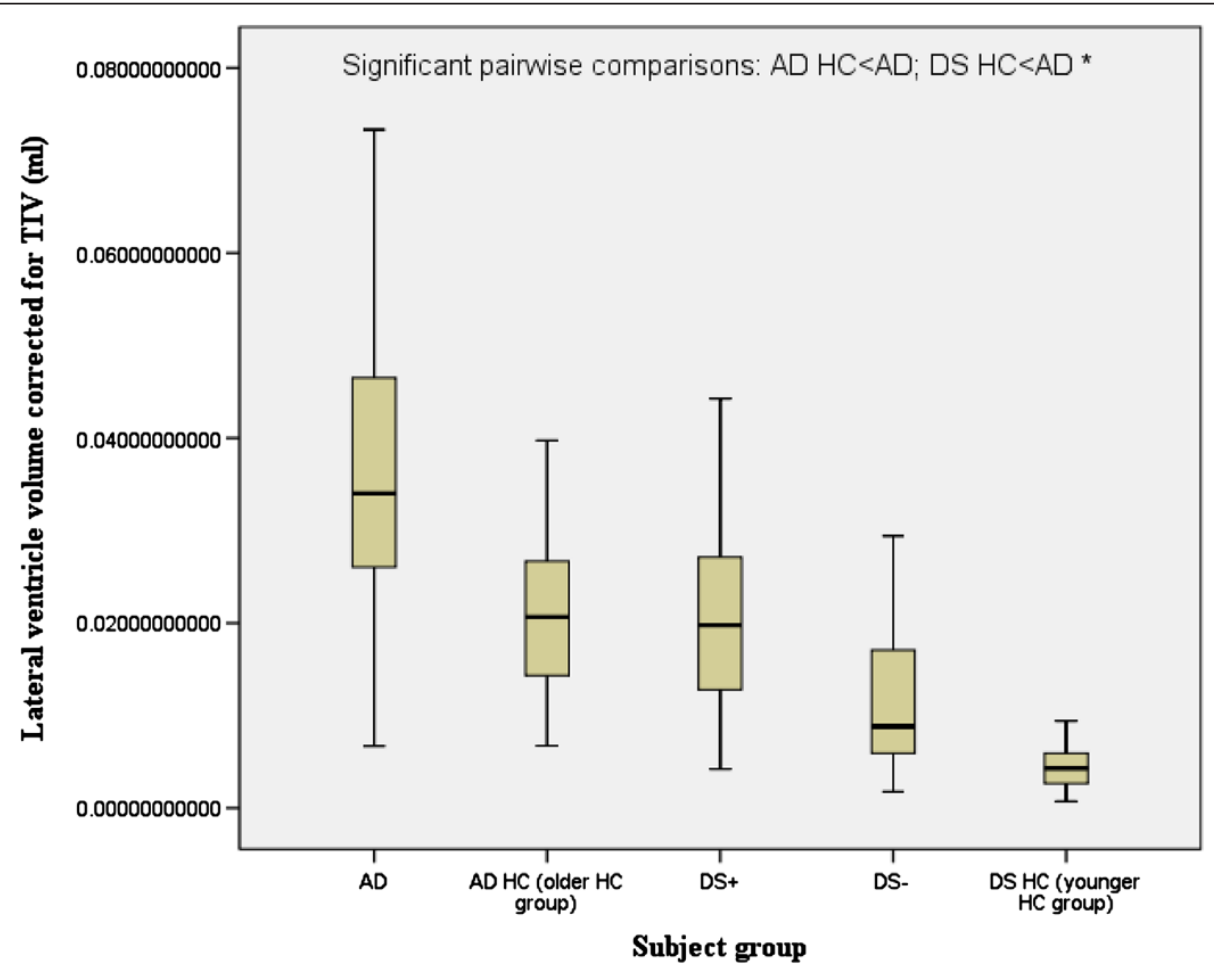

Figure 4 Lateral ventricle volume corrected for total intracranial volume (TIV) (corrected as a ratio of the lateral ventricle volume to TIV). Comparison of people with Alzheimer's disease (AD) and people with Down's syndrome with dementia (DS+). HC, healthy controls; DS-, people with Down's syndrome without dementia. ${ }^{*} P<0.0001$. 
$\mathrm{AD}$ and DS+. It is not possible to be certain that all of the people with dementia under investigation had $\mathrm{AD}$, as this can only be definitively addressed at autopsy. Nevertheless, all the individuals with dementia from both groups (DS and AD in the general population) were diagnosed using standardised instruments and individuals with detectable cerebrovascular disease were excluded. Therefore, the group differences found in regional brain volume between $\mathrm{DS}+$ and $\mathrm{AD}$ in the general population most probably reflect AD-type neuropathology. The sample in this study was characterized with $\mathrm{AD}$ using identical methods to those previously reported and accepted for publication by other high impact factor journals $[5,9,36]$.

Our research laboratory has significant experience in the use of Measure software and our inter-rater and intra-rater correlation coefficients were $>0.9$. Due to our experience of this software, we chose to use it in this study. However, there are other packages, namely the semi-automated package, FreeSurfer, which can produce more detailed metrics, including information on cortical thickness.

\section{Conclusion}

To our knowledge, this is the first study to compare the anatomy of DS+ with individuals with AD. While similar deficits existed in both DS+ and people with AD, namely, reduced volume of the hippocampus and temporal lobe regions compared to their respective control groups, it is possible that less significant regional brain volume reductions are required for the presence of dementia in people with DS. This is potentially explained by their lower cognitive reserve.

\section{Abbreviations \\ AChE: Acetylcholinesterase; AD: Alzheimer's disease; APP: Amyloid precursor protein; CAMCOG: Cambridge cognitive examination; CSF: Cerebrospinal fluid; DS: Down's syndrome; DS+: People with Down's syndrome and dementia; DS-: People with Down's syndrome without dementia; HC: Healthy controls; ICD-10: International classification of diseases-10; ml: Myo-inositol; MMSE: Mini mental state examination; MRI: Magnetic resonance imaging; NINCDS-ADRDA: National Institute of Neurological and Communicative Disorders and Stroke and Alzheimer's Disease and Related Disorders Association; ROI: Region of interest; SPGR: steady state; TE: Echo time; TI: Inversion time; TR: Repetition time; TIV: Total intracranial volume; WBV: Whole brain volume.}

\section{Competing interests}

All authors declare that they have no competing interests.

\section{Authors' contributions}

DM undertook the analysis and interpretation of data, and drafting the article. DM, BH, KCM and DGM revised the article critically for important intellectual content. All authors were involved in the conception and design of the study, and the final approval of the version to be published.

\section{Acknowledgement}

We would like to express our thanks for grant support from: The Baily Thomas Charitable Fund, Alzheimer's Research Trust; NIHR Biomedical Research Centre for Mental Health at South London and Maudsley NHS Foundation Trust and Institute of Psychiatry, King's College London; South London and Maudsley NHS Foundation Trust; MRC UK AIMS programme;
Alzheimer's Research UK; NIHR Biomedical Research Unit for Dementia at South London and Maudsley NHS Foundation Trust and Institute of Psychiatry, King's College London.

\section{Grant support}

The Baily Thomas Charitable Fund, Alzheimer's Research Trust; NIHR Biomedical Research Centre for Mental Health at South London and Maudsley NHS Foundation Trust and Institute of Psychiatry, King's College London; South London and Maudsley NHS Foundation Trust; MRC UK AIMS programme; Alzheimer's Research UK; NIHR Biomedical Research Unit for Dementia at South London and Maudsley NHS Foundation Trust and Institute of Psychiatry, King's College London.

\section{Author details}

'Department of Forensic and Neurodevelopmental Sciences, Section of Brain Maturation, Institute of Psychiatry, De Crespigny Park, London, England, UK. ${ }^{2}$ Department of Psychiatry, Royal College of Surgeons in Ireland, Education and Research Centre, Beaumont Hospital, Dublin 9, Ireland. ${ }^{3}$ Department of Neuroimaging, Institute of Psychiatry, King's College London, London, England, UK. ${ }^{4} \mathrm{NIHR}$ Biomedical Research Centre for Medical Health at the South London and Maudsley NHS Foundation Trust and King's College London, Institute of Psychiatry, London, England, UK. ${ }^{5}$ Section of Old Age Psychiatry, Institute of Psychiatry, De Crespigny Park, London, England, UK.

${ }^{6} \mathrm{MRC}$ Centre for Neurodegeneration Research, Section of Old Age Psychiatry, Institute of Psychiatry, King's College London, London, England, UK.

${ }^{7}$ Department of Psychiatry, Clinical Science Institute, National University of Ireland Galway, Galway, Ireland.

Received: 26 November 2012 Accepted: 30 July 2013

Published: 20 August 2013

\section{References}

1. Evans DA, Funkenstein HH, Albert MS, Scherr PA, Cook NR, Chown MJ, Helbert LE, Hennekens CH, Taylor JO: Prevalence of Alzheimer's disease in a community population of older persons. Higher than previously reported. JAMA 1989, 262:2551-2556.

2. Mann DMA: Alzheimer's disease and Down syndrome. Histopathology 1988, 13:125-137

3. Prasher VP, Farrer MJ, Kessling AM, Fisher EM, West RJ, Barber PC, Butler AC: Molecular mapping of Alzheimer-type dementia in Down's syndrome. Ann Neurol 1998, 43:380-383.

4. Folin M, Baiguera S, Conconi MT, Pati T, Grandi C, Parnigotto PP, Nussdorfer GG: The impact of risk factors of Alzheimer's disease in the Down syndrome. Int J Mol Med 2003, 11:267-270.

5. Beacher F, Simmons A, Daly E, Prasher V, Adams C, Margallo-Lana ML, Morris R Lovestone S, Murphy K, Murphy DG: Hippocampal myo-inositol and cognitive ability in adults with Down syndrome. An in vivo proton magnetic resonance spectroscopy study. Arch Gen Psychiatry 2005, 62:1360-1365.

6. Giesel FL, Hahn HK, Thomann PA, Widjaja E, Wignall E, von Tengg-Kobligk H, Pantel J, Griffiths PD, Peitgen HO, Schroder J, Essig M: Temporal horn index and volume of medial temporal lobe atrophy using a new semiautomated method for rapid and precise assessment. Am J Neuroradio/ 2006, 27:1454-1458.

7. McLaurin J, Franklin T, Chakrabartty A, Fraser PE: Phosphatidylinositol and inositol involvement in Alzheimer amyloid-beta fibril growth and arrest. J Mol Biol 1998, 278:183-194.

8. Foy CML, Daly E, Glover A, O'Gorman R, Simmons A, Murphy DGM, Lovestone S: Hippocampal proton MR spectroscopy in early Alzheimer's Disease and mild cognitive impairment. Brain Topogr 2001, 24:316-322

9. Lamar M, Foy CML, Beacher F, Daly E, Poppe M, Archer N, Prasher V, Murphy KC, Morris RG, Simmons A, Lovestone S, Murphy DG: Down syndrome with and without dementia: an in vivo proton magnetic resonance spectroscopy study with implications for Alzheimer's disease. Neuroimage 2011, 57:63-69.

10. Katzman R, Terry R, DeTeresa R, Brown T, Davies P, Fuld P, Renbing X, Peck $A$ : Clinical, pathological, and neurochemical changes in dementia: a subgroup with preserved mental status and numerous neocortical plaques. Ann Neurol 1988, 23:138-144.

11. Setern $Y$ : What is cognitive reserve? Theory and research application of the reserve concept. J Int Neuropsychol Soc 2002, 8:448-460. 
12. Stern YP: Cognitive reserve and Alzheimer's disease. Alzheimer's Dis Assoc Disord 2006, 20:69-74.

13. Melzer D, Ely M, Brayne C: Cognitive impairment in elderly people: population based estimate of the future in England. Scotland and Wales. BMJ 1997, 315:462

14. McKhann G, Drachman D, Folstein M, Katzman R, Price D, Stadlan EM: Clinical diagnosis of Alzheimer's disease: report of the NINCDS-ADRDS Work Group under the auspices of Department of Health and Human Services Task Force on Alzheimer's Disease. Neurology 1984, 34:939-944.

15. Jack CR Jr, Petersen RC, Xu YC, Waring SC, O'Brien PC, Tangalos EG, Smith $\mathrm{GE}$, Ivnik RJ, Kokmen E: Medial temporal atrophy on MRI in normal aging and very mild Alzheimer's disease. Neurology 1997, 49:786-794.

16. Leinsinger G, Teipel S, Wismuller A, Born C, Meindl T, Flatz W, Schonberg S, Pruessner J, Hampel H, Reiser M: Volumetric MRI for evaluation of regional pattern and progression of neocortical degeneration in Alzheimer's disease. Radiologe 2003, 43:537-542.

17. Jack CR Jr, Shiung MM, Gunter JL, O'Brien PC, Weigand SD, Knopman DS, Boeve BF, Invik RJ, Smith GE, Cha RH, Tangalos EG, Petersen RC: Comparison of different MRI brain atrophy rate measures with clinical disease progression in AD. Neurology 2004, 62:591-600.

18. Devanand DP, Pradhaban G, Liu X, Khandji A, De Santi S, Segal S, Rusinek H, Pelton GH, Honig LS, Mayeux R, Stern Y, Tabert MH, de Leon ML: Hippocampal and entorhinal atrophy in mild cognitive impairment: prediction of Alzheimer disease. Neurology 2007, 68:828-836.

19. Fox NC, Freeborough PA: Brain atrophy progression measured from registered serial MRI: validation and application to Alzheimer's disease. JMRI 1997, 7:1069-1075.

20. Fox NC, Cousens S, Scahill R, Harvey RJ, Rossor MN: Using serial registered brain magnetic resonance imaging to measure disease progression in Alzheimer disease: power calculations and estimates of sample size to detect treatment effects. Arch Neurol 2000, 57:339-344.

21. Smith SM, Zhang Y, Jenkinson M, Chen J, Matthews PM, Federico A, De Stefano N: Accurate, robust, and automated longitudinal and crosssectional brain change analysis. Neuroimage 2002, 17:479-489.

22. Schott JM, Price SL, Frost C, Whitwell JL, Rossor MN, Fox NC: Measuring atrophy in Alzheimer disease: a serial MRI study over 6 and 12 months. Neurology 2005, 65:119-124.

23. Westman E, Wahlund LO, Foy C, Poppe M, Cooper A, Murphy D, Spenger C, Lovestone S, Simmons A: Combining MRS and MRI measures to distinguish between Alzheimer's disease and healthy controls. J Alzheimer's Disease 2010, 22:171-181.

24. Westman E, Wahlund LO, Foy C, Poppe M, Cooper A, Murphy D, Spenger C, Lovestone S, Simmons A: Magnetic resonance imaging and magnetic resonance spectroscopy for detection of early Alzheimer's disease. J Alzheimer's Disease 2001, 26:307-319.

25. Bradley KM, Bydder GM, Budge MM, Hajnal JV, White SJ, Ripley BD, Smith $A D$ : Serial brain MRI at 3-6 month intervals as a surrogate marker for Alzheimer's disease. Br J Radiol 2002, 75:506-513.

26. Wang D, Chalk JB, Rose SE, de Zubicaray G, Cowin G, Galloway GJ, Barnes D, Spooner D, Doddrell MD, Semple J: MR image-based measurement of rates of change in volumes of brain structures part II: application to a study of Alzheimer's disease and normal aging. Magn Reson Imaging 2002, 20:41-48.

27. Silbert LC, Quinn JF, Moore MM, Corbridge E, Ball MJ, Murdoch G, Sexton G, Kaye JA: Changes in premorbid brain volume predict Alzheimer's disease pathology. Neurology 2003, 61:487-492.

28. Thompson PM, Hayashi KM, De Zubicaray Gl, Janke AL, Rose SE, Semple J, Kong MS, Herman DH, Gravano D, Doddrell DM, Toga AW: Mapping hippocampal and ventricular change in Alzheimer disease. Neuroimage 2004, 22:1754-1766.

29. Carmichael OT, Kuller LH, Lopez OL, Thompson PM, Dutton RA, Lu A, Lee SE, Lee YJ, Aizenstein HJ, Meltzer CC, Liu Y, Toga AW, Becker JT: Ventricular volume and dementia progression in the cardiovascular health study. Neurobiol Aging 2007, 28:389-397.

30. Fleisher AS, Sun S, Taylor C, Ward CP, Gamst AC, Petersen RC, Jack CR Jr, Aisen PS, Thal LJ: Volumetric MRI vs clinical predictors of Alzheimer disease in mild cognitive impairment. Neurology 2008, 70:191-199.

31. Xanthakos S, Krishnan KR, Kim DM, Charles HC: Magnetic resonance imaging of Alzheimer's disease. Prog Neuropsychopharmacol Biol Psychiatry 1996, 20:597-626.

32. Kesslak JP, Nagata SF, Lott I, Nalciogly O: MRI analysis of age-related changes in the brains of individuals with Down's syndrome. Neurology 1994, 44:1039-1045.
33. Pearlson GD, Breiter SN, Aylward EH, Warren AC, Grygorcewicz M, Frangou S, Barta PE, Pulsifer MB: MRI brain changes in subjects with Down syndrome with and without dementia. Dev Med Child Neurol 1998, 40:326-334.

34. Aylward EH, Li Q, Honeycutt NA, Warren AC, Pulsifer MB, Barta PE, Chan MD, Smith PD, Jerram M, Pearlson GD: MRI volumes of the hippocampus and amygdala in adults with Down's syndrome with and without dementia. Am J Psychiatry 1990, 156:564-568.

35. Prasher V, Cumella S, Natarajan K, Rolfe E, Shah S, Haque MS: Magnetic resonance imaging, Down's syndrome and Alzheimer's disease: research and clinical implications. JIDR 2003, 47:90-100.

36. Beacher F, Daly E, Simmons A, Prasher V, Morris R, Robinson C, Lovestone S, Murphy K, Murphy DG: Alzheimer's disease and Down's syndrome: an in vivo MRI study. Psychol Med 2009, 39:675-683.

37. Hon J, Huppert F, Holland A, Watson P: Neuropsychological assessment of older adults with Down's syndrome: an epidemiological study using the Cambridge Cognitive Examination (CAMCOG). Br J Clin Psych 1999, 38:155-165.

38. Blessed G, Black SE, Butler T, Kay DW: The diagnosis of dementia in the elderly. A comparison of CAMCOG (the cognitive section of CAMDEX), the AGECAT program, DSM-III, the Mini-Mental State Examination and some short rating scales. Br J Psychiatry 1991, 159:193-198.

39. Simmons A, Arridge SR, Barker GJ, Williams SC: Stimulation of MRI cluster plots and application to neurological segmentation. Magn Reson Imaging 1996, 14:73-92.

40. Simmons A, Westman E, Muehlboeck S, Mecocci P, Vellas B, Tsolaki M, Kloszewska I, Wahlund LO, Soininen H, Lovestone S, Evans A, Spenger C: AddNeuroMed Consortium. MRI measures of Alzheimer's disease and the AddNeuroMed study. Ann NY Acad Sci 2009, 1180:47-55.

41. Simmons A, Westman E, Muehlboeck S, Mecocci P, Vellas B, Tsolaki M, Kloszewska I, Wahlund LO, Soininen H, Lovestone S, Evans A, Spenger C: The AddNeuroMed framework for multi-centre MRI assessment of Alzheimer's disease: experience from the first 24 months. Int J Geriatr Psychiatry 2011, 26:75-82.

42. Barta PE, Dhingra L, Royall R, Schwartz E: Efficient estimates for the volume of structures identified in three-dimensional arrays of spatial data. J Neurosci Methods 1997, 75:111-118.

43. Murphy DGM, DeCarli C, Mclntosh AR, Daly E, Mentis MJ, Pietrini P, Szcepanik J, Schapiro MB, Grady CL, Horowitz B, Rapoport SI: Sex differences in human brain morphometry and metabolism: an in vivo quantitative magnetic resonance imaging and positron emission tomography study on the effect of aging. Arch Gen Psychiatry 1996, 53:585-594.

44. Murphy DGM, DeCarli C, Daly E, Haxby JV, Allen G, White BJ, McIntosh AR, Powell CM, Horowitz B, Rapoport SI, Schapiro MB: X-chromosome effects on female brain: a magnetic resonance imaging study of Turner's syndrome. Lancet 1993, 342:1197-2000

45. Watson C, Andermann F, Gloor P, Jones-Gotman M, Peters T, Evans A, Olivier A, Melnson D, Leroux G: Anatomic basis of amygdaloid and hippocampal volume measurement by magnetic resonance imaging. Neurology 1992, 42:1743-1750.

46. Bartko JJ, Carpenter WT: On the methods and theory of reliability. J Nervous Ment Disease 1986, 163:307-317.

47. Wisniewski KE, Dalton AJ, McLachlan C, Wen GY, Wisniewski HM: Alzheimer's disease in Down's syndrome: clinicopathologic studies. Neurology 1985, 35:957-961.

48. Oliver C, Holland AJ: Down's syndrome and Alzheimer's disease: a review. Psychol Med 1986, 16:307-322.

49. Lott IT, Head E: Down syndrome and Alzheimer's disease: a link between development and aging. Ment Retard Dev Disabil Res Rev 2001, 7:172-178.

50. Raz N, Torres IJ, Briggs SD, Spencer WD, Thornton AE, Loken WJ, Gunning FM, McQuain JD, Driesen NR, Acker JD: Selective neuroanatomic abnormalities in Down's syndrome and their cognitive correlates: evidence from MRI morphometry. Neurology 1995, 45:356-366.

51. Aylward EH, Qiang L, Honeycutt NA, Warren AC, Pulsifer MB, Barta PE, Chan $M D$, Smith PD, Jerram M, Pearlson GD: MRI volumes of the hippocampus and amygdala in adults with Down's syndrome with and without dementia. Am J Psychiatry 1999, 156:564-568.

52. Beacher F, Daly E, Simmons A, Prasher V, Morris R, Robinson C, Lovestone S, Murphy K, Murphy DG: Brain anatomy and ageing in non-demented adults with Down's syndrome: an in vivo MRI study. Psychol Med 2010, 40:611-619.

53. Double KL, Halliday GM, Kril JJ, Harasty JA, Cullen K, Brooks WS, Creasey H, Broe GA: Topography of brain atrophy during normal ageing and AD. Neurobiol Aging 1996, 17:513-521. 
54. Karas GB, Burton EJ, Rombouts SA, van Schijndel RA, O'Brien JT, Scheltens P, McKeith IG, Williams D, Ballard C, Barkhof F: A comprehensive study of gray matter loss in patients with Alzheimer's disease using optimized voxel-based morphometry. Neuroimage 2003, 18:895-907.

55. Pennanen $C$, Kivipelto M, Tuomainen S, Hartikainen $P$, Hanninen $T$, Laakso MP, Hallikainen M, Vanhanen M, Nissinen A, Helkala EL, Vainio P, Vanninen R, Partanen K, Soininen H: Hippocampus and entorhinal cortex in mild cognitive impairment and early AD. Neurobiol Aging 2004, 25:303-310.

56. Hessl D, Rivera S, Koldewyn K, Cordeiro L, Adams J, Tassone F, Hagerman PJ, Hagerman RJ: Amygdala dysfunction in men with the fragile $X$ premutation. Brain 2007, 130:404-416.

57. Schumann CM, Hamstra J, Goodlin-Jones BL, Lotspeich LJ, Kwon H, Buonocore $\mathrm{MH}$, Lammers CR, Reiss A, Amaral DG: The amygdala is enlarged in children but not adolescents with autism; the hippocampus is enlarged at all ages. J Neuroscience 2004, 24:6392-6401.

58. Krasuski JS, Alexander GE, Horwitz B, Rapoport SI, Schapiro MB: Relation of medial temporal lobe volumes to age and memory function in nondemented adults with Down's syndrome: implications for the prodromal phase of Alzheimer's disease. Am J Psychiatry 2002, 159:74-81.

59. Pinter JD, Brown WE, Eliez S, Schmitt JE, Capone GT, Reiss AL: Amygdala and hippocampal volumes in children with Down Syndrome: a highresolution MRI study. Neurology 2001, 56:972-974.

60. Teipel SJ, Schapiro MB, Alexander GE, Krasuski JS, Horwitz B, Hoehne C, Moller HJ, Rapoport SI, Hampel H: Relation of corpus callosum and hippocampal size to age in non-demented adults with Down's syndrome. Am J Psychiatry 2003, 160:1870-1878.

61. Ball MJ, Schapiro MB, Rapoport SI: Neuropathological relationships between Down syndrome and senile dementia Alzheimer type. In Neurobiology of Down syndrome. Edited by Epstein C. New York: Raven Press; 1986:45-58.

62. Mann DMA, Esiri MM: The pattern of acquisition of plaques and tangles in the brains of patients under 50 years of age with Down's syndrome. J Neurol Sci 1989, 89:169-179.

63. Hof PR, Bouras C, Perl DP, Sparks L, Mehta N, Morrison JH: Age-related distribution of neuropathologic changes in the cerebral cortex of patients with Down's syndrome: quantative regional analysis and comparison with Alzheimer's disease. Arch Neurol 1995, 52:379-391.

64. Hyman BT, West HL, Rebeck GW, Lai F, Mann DMA: Neuropathological changes in Down's syndrome hippocampal formation: effect of age and apolipoprotein E genotype. Arch Neurol 1995, 52:373-378.

65. Laakso MP, Soininen $H$, Partanen $K$, Helkala EL, Hartikainen P, Vainio P, Hallikainen M, Hanninen T, Riekkinen PJ Sr: Volumes of hippocampus, amygdala and frontal lobes in the MRI-based diagnosis of early Alzheimer's disease: correlation with memory functions. J Neural Transm 1995, 9:73-86.

66. Yamaguchi S, Meguro K, Shimada M, Ishizaki J, Yamadori A, Sekita Y: Five year retrospective changes in hippocampal atrophy and cognitive screening test performances in very mild Alzheimer's disease: the Tajiri project. Neuroradiology 2002, 44:43-48.

67. Seab JB, Jagust WJ, Wong STS, Roos MS, Reed BR, Budinger TF: Quantitative NMR measurements of hippocampal atrophy in Alzheimer's disease. Magn Reson Med 1988, 8:200-208.

68. Mega MS, Thompson PM, Toga AW, Cummings JL: Brain mapping in dementia. In Brain mapping: the disorders. Edited by Mazziotta J, Frackowiak RSJ, Toga A. San Diego: Academic Press; 2000:217-239.

69. Fox NC, Rossor MN: Diagnosis of early Alzheimer's disease. Rev Neurol 1999, 155(suppl 4):S33-S37

70. Celsis P: Age-related cognitive decline, mild cognitive impairment or preclinical Alzheimer's disease? Ann Med 2000, 32:6-14.

71. Scheltens P: Early diagnosis of dementia: neuroimaging. J Neurol 1999, 246:16-20.

72. Jack CR Jr, Dickson DW, Parisi JE, Xu YC, Cha RH, O'Brien PC, Edland SD, Smith GE, Boeve BF, Tangalos EG, Kokmen E, Petersen RC: Antemortem MRI findings correlate with hippocampal neuropathology in typical aging and dementia. Neurology 2002, 58:750-757.

73. Riekkinen P Jr, Kejonen K, Laakso MP, Soininen H, Partanen K, Riekkinen M: Hippocampal atrophy is related to impaired memory, but not frontal functions in non-demented Parkinson's disease patients. Neuroreport 1998, 9:1507-1511.
74. Gosche KM, Mortimer JA, Smith CD, Markesbery WR, Snowdon DA Hippocampal volume as an index of Alzheimer neuropathology: findings from the Nun study. Neurology 2002, 58:1476-1482.

75. Kesslak JP, Nalcioglu O, Cotman CW: Quantification of magnetic resonance scans for hippocampal and parahippocampal atrophy in Alzheimer's disease. Neurology 1991, 41:51-54.

76. Pearlson GD, Harris GJ, Powers RE: Quantitative changes in mesial temporal volume, regional cerebral blood flow, and cognition in Alzheimer's disease. Arch Gen Psychiatry 1992, 49:402-408.

77. Jack CR Jr, Petersen RC, O'Brien PC, Tangalos EG: MR-based hippocampal volumetry in the diagnosis of Alzheimer's disease. Neurology 1992, 42:183-188.

78. Killiany RJ, Moss MB, Albert MS, Sandor T, Tieman J, Jolesz F: Temporal lobe regions on magnetic resonance imaging identify patients with early Alzheimer's disease. Arch Neurol 1993, 50:949-954.

79. Convit A, de Leon MJ, Golomb J, George AE, Tarshish CY, Bobinski M, Tsui W, De Santi S, Wegiel J, Wisniewski H: Hippocampal atrophy in early Alzheimer's disease, anatomic specificity and validation. Psychiatr Q 1993, 64:371-387.

80. Lehericy S, Baulac M, Chiras J, Pierot L, Martin N, Pillon B, Deweer B, Dubois $B$, Marsault C: Amygdalohippocampal MR volume measurements in the early stages of Alzheimer disease. Am J Neuroradiol 1994, 15:929-937.

81. Squire LR, Zola-Morgan S: The medial temporal lobe memory system. Science 1991, 20:1380-1386.

82. Rombouts S, Machielsen W, Witter M, Barkhof F, Lindeboom J, Scheltens P: Visual association encoding activates the medial temporal lobe: a functional magnetic resonance imaging study. Hippocampus 1997, 7:594-601.

83. Storandt $M$, Hill R: Very mild senile dementia of the Alzheimer type-II Psychometric test performance. Arch Neurol 1989, 46:383-386.

84. Petersen RC, Smith GE, Ivnik RJ, Tangalos EG: Memory function in very early Alzheimer's disease. Neurology 1994, 44:867-872.

85. Linn RT, Wolf PA, Bachman DL, Knoefel JE, Cobb JL, Belanger AJ, Kaplan EF, D'Agostino RB: The 'preclinical phase' of probable Alzheimer's disease. Arch Neurol 1995, 52:485-490.

86. Tierney M, Szalai J, Snow W: Prediction of probable Alzheimer's disease in memory impaired patients. Neurology 1996, 46:661-665.

87. Bowen J, Teri L, Kukull W, McCormick W, McCurry S, Larson E: Progression to dementia in patients with isolated memory loss. Lancet 1997, 349:763-765.

88. De Leon M, George A, Convit A, Tarshish CY, McRae T, De Santi S, Smith G, Ferris SH, Noz M, Rusinek H: The radiologic prediction of Alzheimer disease: the atrophic hippocampal formation. Am J Neuroradiol 1993, 14:897-906.

89. Kaye JA, Swihart T, Howieson D, Dame A, Moore MM, Karnost T, Camicioli R, Ball M, Oken B, Sexton G: Volume loss of the hippocampus and temporal lobe in healthy elderly persons destined to develop dementia. Neurology 1997, 48:1297-1304.

90. Fox NC, Freeborough PA, Rossor MN: Visualisation and quantification of rates of atrophy in Alzeheimer's disease. Lancet 1996, 348:94-97.

91. Meng X, D'Arch C: Education and Dementia in the context of the cognitive research hypothesis: a systematic review with meta-analysis and qualitative analyses. PLOS One 2012, 7:e38268.

92. Temple V, Jozsvai E, Konstantareas MM, Hewitt TA: Alzheimer's dementia in Down's syndrome: the relevance of cognitive ability. J Intell Dis Res 2001, 45:47-55.

93. Golomb J, Kluger A, de Leon M, Ferris SH, Mittelman M, Cohen J, George AE: Hippocampal formation size predicts declining memory performance in normal aging. Neurology 1996, 47:810-813.

94. Aylward EH, Li Q, Habbak QR, Warren A, Pulsifer MB, Barta PE, Jerram M, Pearlson G: Basal ganglia volume in adults with Down syndrome. Psychiatry Res 1997, 74:73-82.

95. Teipel SJ, Alexander GE, Schapiro MB, Moller HJ, Rapoport SI, Hampel H: Age-related cortical grey matter reductions in non-demented Down's syndrome adults determined by MRI with voxel-based morphometry. Brain 2004, 127:811-824

96. Coppus A, Evenhuis H, Verberne GJ, Visser F, van Gool P, Eikelenboom P, van Duijin C: Dementia and mortality in persons with Down's syndrome. JIDR 2006, 50:768-777.

doi:10.1186/1866-1955-5-19

Cite this article as: Mullins et al:: Dementia in Down's syndrome: an MRI comparison with Alzheimer's disease in the general population. Journal of Neurodevelopmental Disorders 2013 5:19. 